\title{
ANATOMIA DA MADEIRA DE SALIX X RUBENS SCHRANK (SALICACEAE) $^{1}$
}

\section{LUCIANO DENARDI ${ }^{2}$ JOSÉ NEWTONCARDOSO MARCHIORI ${ }^{3}$ MIGUELANTÃO DURLO $^{4}$}

\section{RESUMO}

É descrita a anatomia da madeira do caule jovem de Salix x rubens Schrank, com vistas à utilização da espécie em Bioengenharia. Foram observados vasos de pequeno diâmetro $(<90 \mu \mathrm{m})$ e em distribuição semi-difusa, parênquima axial escasso, presente no término do anel, raios heterogêneos exclusivamente unisseriados e abundantes fibras gelatinosas.

\section{ABSTRACT}

[Wood anatomy of Salix x rubens Schrank (Salicaceae)].

The wood anatomy of Salix x rubens Schrank is described, based on young stems, used in Bioengeneering. The anatomical structure shows a semi-difuse porous wood, small diameter vessels $(<90 \mu \mathrm{m})$, rare marginal axial parenchyma, heterogeneous and only uniseriate rays, and abundant gelatinous fibres.

\section{INTRODUÇÃO}

Até bem pouco tempo, a família Salicaceae compunha-se apenas dos gêneros Salix e Populus. A partir de estudos recentes de filogenia, a mesma passou a incorporar outros gêneros, antes incluídos em Flacourtiaceae, tais como Azara, Banara, Casearia e Xylosma (Souza \& Lorenzi, 2005), reunindo árvores, arbustos e, menos freqüentemente, lianas, por vezes armados de espinhos. De distribuição cosmopolita, a família inclui, atualmente, cerca de 50 gêneros e 1.000 espécies. O Brasil é representado por 10 gêneros e aproximadamente 80 espécies.

Salix x rubens Schrank é um híbrido resultante do cruzamento de duas espécies européias: Salix alba e Salix fragilis (Hörandl, 1992; Salzmann, 1988; Moura, 2002). O vimeiro ou vime, como é popularmente conhecido, é planta lenhosa de tronco geralmente único e muito ramificado, que pode atingir mais de $15 \mathrm{~m}$ de altu- ra. A espécie foi introduzida no Brasil na primeira metade do século $\mathrm{XX}$, por imigrantes italianos, com a finalidade de amarrar parreirais e para a confecção de cestas (Gobbato, 1954; Silva, 1999). Assim como na Europa, no sul do Brasil o vimeiro vem recebendo especial atenção para o uso em Bioengenharia, com vistas à proteção de taludes fluviais (Sutili, 2004; Durlo \& Sutili, 2005; Denardi, 2007).

Com relação à estrutura anatômica da madeira de Salix x rubens, a única referência, ao que tudo indica, deve-se a Wagner (2005). A descrição anatômica feita por esta autora, e que será parcialmente reproduzida a seguir, referese à madeira proveniente do caule de plantas com idade inferior a 1 ano: ausência de anéis de crescimento; vasos solitários ou em múltiplos radiais de $2-3$, e com freqüência em torno de $120 / \mathrm{mm}^{2}$; elementos vasculares com $450 \mu \mathrm{m}$ de comprimento por $55 \mu \mathrm{m}$ de diâmetro, aproximadamente, com placas de perfuração simples; pontoações intervasculares alternas e poligonais;

' Artigo recebido em 02/05/2008 e aceito para publicação em 29/05/2008.

2 Engenheiro Florestal, Doutor, Professor Adjunto do Departamento de Engenharia Florestal, Universidade Federal de Santa Maria/CESNORS, CEP98400-000, Frederico Westphalen (RS). lucianodenardi@yahoo.com.br

3 Engenheiro Florestal, Dr., bolsista de produtividade em Pesquisa do CNPq-Brasil, Professor Titular do Departamento de Ciências Florestais, Universidade Federal de Santa Maria, CEP 97105-900, Santa Maria (RS). Balduinia@ mail.ufsm.br 
pontoações raio-vasculares com bordas diminutas; parênquima axial ausente; raios exclusivamente unisseriados, compostos por células procumbentes, quadradas e eretas; fibras com cerca de $700 \mu \mathrm{m}$ de comprimento, não septadas e providas de pontoações simples na parede.

Para os gêneros Salix e Populus, cabe agregar que o lenho é constituído principalmente por fibras $(56-79 \%)$, vasos $(20-33 \%)$, raios e parênquima axial, sendo que estes últimos tecidos somam entre 3 e 10\% (FAO, 1980).

\section{MATERIAL E MÉTODOS}

O material em estudo foi coletado na sede do município de Santa Maria - RS, às margens do Arroio Cadena. As exsicatas e a amostra de madeira foram anexadas no Herbário e Xiloteca do Departamento de Ciências Florestais da Universidade Federal de Santa Maria (HDCF), sob o número 5594.

Da amostra de madeira, extraída do caule de um indivíduo de $6,8 \mathrm{~cm}$ de diâmetro (à altura do peito), foram confeccionados três corpos-deprova, orientados para a obtenção de cortes nos planos anatômicos transversal, longitudinal radial e longitudinal tangencial. O preparo de lâminas histológicas seguiu a técnica padrão: após fervura em água os corpos-de-prova foram seccionados em micrótomo de deslize, coloridos com acridina-vermelha, crisoidina e azul-de-astra (Dujardin, 1964), desidratados em série alcoólica crescente e diafanizados com xilol. Em seguida, foram montadas lâminas permanentes, usando-se "Entellan" como meio de montagem.

Para a dissociação do tecido lenhoso, usouse o método de Jeffrey, conforme descrito em Burger \& Richter (1991): solução aquosa de ácido nítrico e ácido crômico, ambos a 10\%, na proporção 1:1, em dois banhos sucessivos de 24 horas cada. Concluída a maceração, a "pasta" de células foi depositada em funil com papel de filtro, onde procedeu-se a coloração com solução de safranina $1 \%$. As etapas seguintes (desidratação, diafanização e montagem de lâmi- nas permanentes) seguiram as mesmas orientações adotadas no preparo de lâminas histológicas, com a diferença de que as duas primeiras etapas foram realizadas sobre papel de filtro.

A descrição microscópica baseou-se nas normas do IAWA Committee (1989). Para a determinação da fração de tecidos, seguiu-se a metodologia proposta por Marchiori (1980). As fotomicrografias da madeira foram obtidas com o uso de um microscópio Olympus CX-40, com câmera digital acoplada.

Os dados quantitativos, bem como as fotomicrografias do lenho estão reunidos na Tabela 1 e Figura 1, respectivamente.

\section{DESCRIÇÃO MICROSCÓPICA}

Aspectos gerais: lenho composto principalmente por fibras (58\%), seguido de vasos (30\%), raios (10\%) e apenas $1 \%$ de parênquima axial. Anéis de crescimento demarcados usualmente por uma camada de fibras radialmente achatadas e com paredes relativamente espessas ao final do lenho tardio, bem como pelos poros de maior diâmetro, no início do anel seguinte (Figura $1 \mathrm{~A}, \mathrm{~B})$.

Vasos: em distribuição semi-difusa, solitários ou dispostos em múltiplos radiais de $2-3$ (Figura 1A), com frequiência de $87 \pm 30$ (50 $125)^{*}$ vasos $/ \mathrm{mm}^{2}$. De seção poligonal, medem $57 \pm 10(34-82) \mu \mathrm{m}$ de diâmetro, com paredes de $3 \pm 0,7(1,5-4,1) \mu \mathrm{m}$ de espessura. Elementos vasculares de $383 \pm 66(250-490) \mu \mathrm{m}$ de comprimento, com placas de perfuração simples, oblíquas (Figura 1D, F), raramente providos de apêndices. Espessamentos helicoidais, tiloses e depósitos, ausentes. Pontoações intervasculares alternas, poligonais, de 7,7-9,2 $\mu \mathrm{m}$ de diâmetro e com aberturas elípticas. Pontoações raio-vasculares poligonais e de bordas reduzidas (aparentemente simples), medindo 4,3-9,2 $\mu \mathrm{m}$ de diâmetro, presentes, sobretudo, nas extremidades dos raios (Figura 1C, D).

Parênquima axial: extremamente escasso e aparentemente marginal, sem formar faixas 
TABELA 1: Dados quantitativos do lenho de Salix x rubens Schrank.

\begin{tabular}{lcccccc}
\hline \multicolumn{1}{c}{ CARACTERES ANATÔMICOS } & $\mathrm{N}$ & $\mathrm{MÍN}$ & $\mathrm{X}$ & $\mathrm{MÁX}$ & $\mathrm{S}$ & $\mathrm{CV}_{\%}$ \\
\hline Fração de vasos $(\%)$ & 6 & 23,0 & 30,3 & 36,0 & 5,6 & 18,5 \\
Freqüência de vasos (vasos $\left./ \mathrm{mm}^{2}\right)$ & 10 & 50,0 & 87,5 & 125,0 & 30,0 & 34,3 \\
Diâmetro do lume de vasos $(\mu \mathrm{m})$ & 40 & 34,1 & 56,7 & 81,8 & 10,4 & 18,3 \\
Espessura da parede de vasos $(\mu \mathrm{m})$ & 40 & 1,5 & 2,8 & 4,1 & 0,7 & 25,0 \\
Comprimento de elementos vasculares $(\mu \mathrm{m})$ & 25 & 250,0 & 382,8 & 490,0 & 66,1 & 17,3 \\
Fração de parênquima axial $(\%)$ & 6 & 1,0 & 1,2 & 2,0 & 0,4 & 33,3 \\
Fração de raios (\%) & 6 & 8,0 & 10,2 & 14,0 & 2,1 & 20,6 \\
Freqüência de raios (raios $/ \mathrm{mm})$ & 10 & 12,0 & 15,7 & 18,0 & 2,1 & 13,4 \\
Altura de raios unisseriados $(\mu \mathrm{m})$ & 25 & 50,2 & 138,6 & 292,1 & 63,9 & 46,1 \\
Largura de raios unissseriados $(\mu \mathrm{m})$ & 25 & 10,2 & 12,3 & 15,1 & 1,3 & 10,6 \\
Fração de fibras $(\%)$ & 6 & 54,0 & 58,3 & 65,0 & 4,6 & 7,9 \\
Comprimento de fibras $(\mu \mathrm{m})$ & 25 & 480,0 & 782,8 & 1160,0 & 178,1 & 22,7 \\
\hline
\end{tabular}

$\mathrm{N}$ = número de observações; $M \mathbf{I I}^{\mathrm{N}}=$ valor mínimo; $\mathrm{X}=$ média; $\mathrm{MÁX}=$ valor máximo; $\mathrm{S}$ = desvio padrão; $\mathrm{CV} \%=$ coeficiente de variação $(\mathrm{S} / \mathrm{X}) \times 100 ; \mu \mathrm{m}=$ micrômetros.

contínuas no limite do anel de crescimento (Figura 1B). Inclusões minerais, ausentes no material estudado.

Raios: com freqüência média de $16 / \mathrm{mm}$ e exclusivamente unisseriados (Figura 1E, F). São heterogêneos, reunindo células procumbentes, eretas e quadradas; medem $139 \pm 64(50-292)$ $\mu \mathrm{m}$ de altura por $12 \pm 1,3(10-15) \mu \mathrm{m}$ de largura. Células perfuradas de raio, canais intercelulares, tubos lactíferos e inclusões minerais, ausentes.

Fibras: não-septadas, de $783 \pm 178(480-$ 1160) $\mu \mathrm{m}$ de comprimento, com paredes muito estreitas (Figura 1B), providas de pontoações simples, com abertura geralmente em forma de fenda. Fibras gelatinosas abundantes, distintas pela coloração atípica e espessamento anormal da parede (Figura 1A, B). Traqueídeos vasculares, traqueídeos vasicêntricos e espessamentos helicoidais, ausentes.

$* \mathrm{x} \pm \mathrm{s}$ (valor mínimo - valor máximo), onde: $\mathrm{x}=$ média; $\mathrm{s}=$ desvio padrão.

\section{ANÁLISE DA ESTRUTURA ANATÔMICA}

A descrição anatômica da madeira de Salix $\mathrm{x}$ rubens Schrank assemelha-se à realizada por
Wagner (2005). Alguns aspectos qualitativos, no entanto, merecem análise mais criteriosa: a) a referida autora, devido ao exame de madeira proveniente de caules muito jovens (com menos de 1 ano), atribuiu precocemente a presença de porosidade difusa, diferentemente do encontrado no presente estudo (porosidade semi-difusa); b) pelo mesmo motivo, provavelmente, não foi referida por Wagner (2005) a presença de parênquima axial, uma vez que o mesmo encontra-se escassamente distribuído no término do anel de crescimento, como presentemente observado.

No que diz respeito à composição do tecido lenhoso, os valores encontrados (fibras $54 \%$, va$\operatorname{sos} 23 \%$, raios $8 \%$ e parênquima axial $1 \%$ ) situam-se dentro do esperado, estando de acordo com o referido, pela FAO (1980), para os gêneros Salix e Populus.

Uma rápida análise comparativa entre a madeira de Salix x rubens e Salix humboldtiana faz-se necessária, uma vez que esta última espécie ocorre naturalmente no Brasil e que as madeiras do gênero são anatomicamente muito semelhantes. De acordo com Denardi et al. (2007), as pontoações das fibras de $S$. humboldtiana possuem aberturas predominan- 

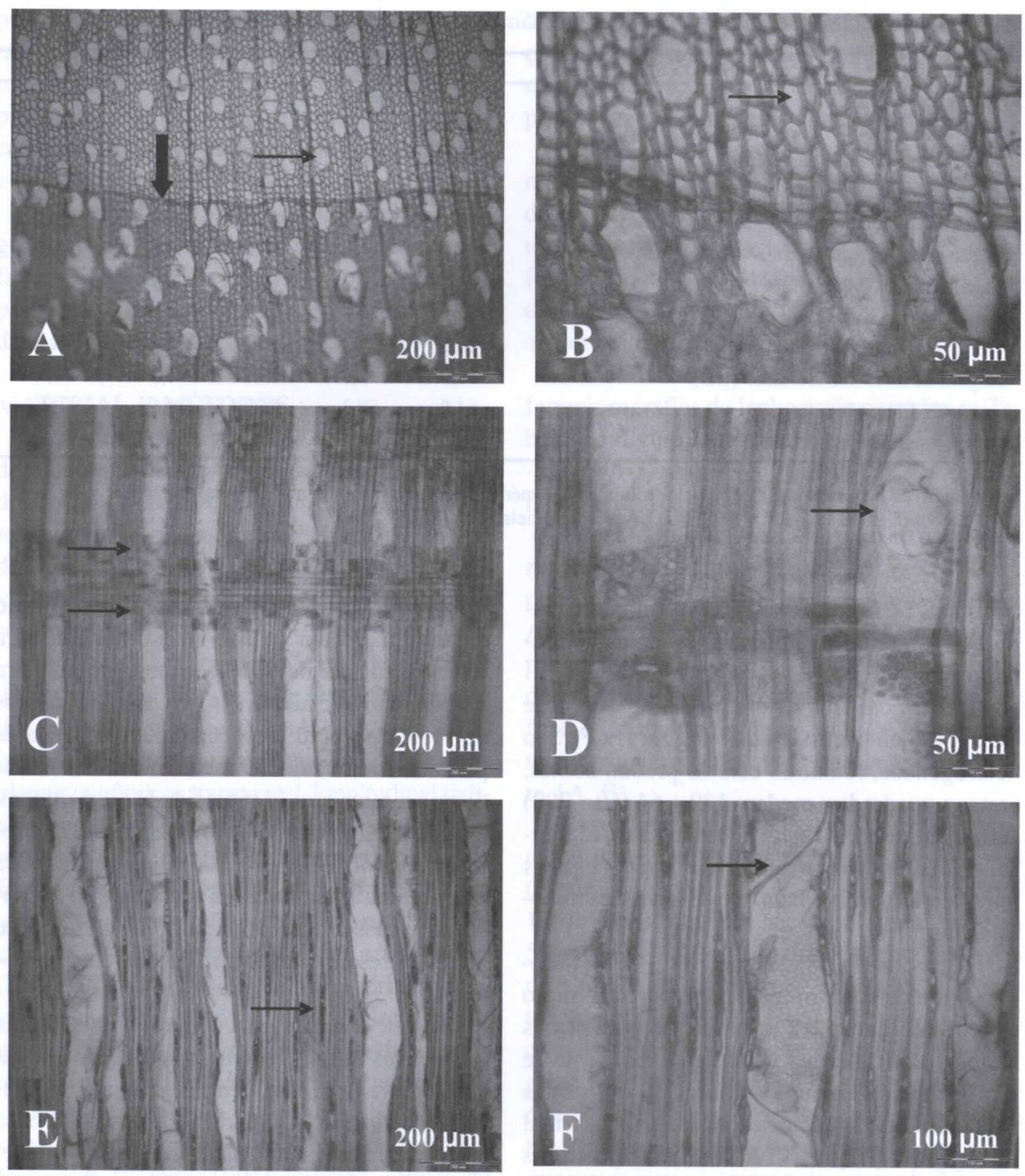

FIGURA 1 - Secção transversal da madeira de Salix x rubens Schrank, destacando a porosidade semi-difusa, vasos solitários ou em múltiplos radiais (seta estreita) e limite de um anel de crescimento (seta larga), em (A). Fibras com paredes muito estreitas (seta) e limite de anel de crescimento, em seção transversal (B). Aspecto geral da madeira em seção longitudinal radial, com destaque para as pontoações raio-vasculares (setas) presentes nas extremidades dos raios (C). Placa de perfuração simples (seta), em seção longitudinal radial (D). Aspecto do plano longitudinal tangencial, destacando os raios (setas) exclusivamente unisseriados (E). Placa de perfuração simples em posição oblíqua (seta), em (F). 
temente arredondadas e o parênquima axial (terminal) forma faixas contínuas de largura variável ( 2 - 3 células); em $S$. x rubens, ao contrário, constatou-se que o parênquima axial dispõese em pequenas linhas tangencias no término do anel de crescimento (sem formar faixas contínuas), e as pontoações das fibras freqüentemente apresentam abertura em forma de fenda.

Ao que tudo indica, a presença abundante de fibras gelatinosas no lenho de Salix x rubens confere maior flexibilidade ao caule, aspecto particularmente importante e de ocorrência freqüente em indivíduos que habitam margens de cursos de água (Denardi 2007). Resta comentar, por fim, que espécies com elevada flexibilidade de caules e ramos são recomendadas pela Bioengenharia, com vistas à proteção de taludes fluviais, por terem maior capacidade de se curvarem, reduzindo a velocidade da água, durante as cheias.

\section{BIBLIOGRAFIA}

Burger, L. M., Richter, H. G. Anatomia da madeira. São Paulo: Ed. Nobel, 1991. 154p.

Denardi, L. Anatomia e flexibilidade do caule de quatro espécies lenhosas, para o manejo biotécnico de cursos de água. Santa Maria: UFSM, 2007. 113p. Tese (Doutorado em Manejo Florestal) Universidade Federal de Santa Maria.

Denardi, L., Marchiori, J.N.C., Santos, S.R. dos. Anatomia da madeira de Salix humboldtiana Willd. (Salicaceae). Balduinia, n. 11, p. 27-31, 2007.

Durlo, M. A., Sutili, F. J. Bioengenharia: manejo biotécnico de cursos de água. Porto Alegre: EST, 2005. 189p.

Dujardin, E. P. Eine neue Holz-Zellulosenfaerbung. Mikrokosmos, n. 53, p. 94, 1964.
FAO. Organizacion de las Naciones Unidas para la Agricultura y la Alimentacion. Los álamos y los sauces em la producción de madera y la utilización de las tierras. Roma: 1980.

Gobbato, C. Cultura do vimeiro. Chácaras e quintais, v. 90 n. 2 , p. $42-43,1954$.

Hörandl, E. Die Gattung Salix in Österreich: mit Berücksichtigung angrenzender gebiete. Wien: 1992.p. 53-54.

IAWA Committee. IAWA list of microscopic features for hardwood identificacion. IAWA Bulletin, v. 10, n. 3, p. 218-359, 1989.

Marchiori, J. N. C. Estudo anatômico do xilema secundário de algumas espécies dos gêneros Acacia e Mimosa, nativas no estado do Rio Grande do Sul. Curitiba: UFPR, 1980. 186f. Dissertação (Mestrado em Engenharia Florestal) - Universidade Federal do Paraná.

Moura, V.P.G. Introdução de novas espécies de Salix (Salicaceae) no Planalto Sul de Santa Catarina, Brasil. Embrapa, 2002 (Comunicado técnico; n. 71).

Salzmann, C. Verwendug Von unterschiedlic langen setztangen der fahzweide (Salix $\mathrm{x}$ rubens) in Lagenbau. Wien: Diplomarbeit, Universität für Bodenkultur, 1988.

Silva, G. Vime cultivo e arte. Revista Globo Rural, v. 15, n. 169, p. 48-52, 1999.

Souza, V. C.; Lorenzi, H. Botânica sistemática: guia ilustrado para identificação das famílias de Angiospermas dicotiledôneas da flora brasileira, baseado em APG II. Nova Odessa, São Paulo: Instituto Plantarum, 2005. 640p.

Sutili, F. J. Manejo biotécnico do arroio Guarda-mor: princípios, processos e práticas. Santa Maria: UFSM, 2004. 114f. Dissertação (Mestrado em Manejo Florestal) - Universidade Federal de Santa Maria.

Wagner, M.A. Morfo-anatomia do caule do vime brasileiro (Salix x rubens Schrank). 2005. 22f. Monografia (Graduação em Ciências Biológicas) - Universidade Federal do Paraná, Curitiba, 2005. 